\title{
Can a Constitutional Monarch Influence Democratic Preferences? The Regulation of Public Expression in Japan
}

\author{
Susumu Annaka*1 and Gento Kato ${ }^{\dagger 2}$ \\ ${ }^{1}$ Waseda University \\ ${ }^{2}$ Nazarbayev University
}

April 3, 2021

\begin{abstract}
This study examines whether non-political symbolic figures, such as the emperor of Japan, have any influence on ideological attitudes under a democracy. We design a unique survey experiment regarding the regulation of public expression. This issue can be framed both as left-wing (i.e., the regulation of hate speech) and right-wing (i.e., the regulation of publicly funded anti-nationalistic exhibitions). Taking advantage of the dual nature of the issue, we test the effects of the emperor's endorsement on support for regulation under each ideological framework. The results indicate that the (former) emperor's endorsement for freedom of expression does have a cross-cutting effect and decreases support for regulation. This effect is relatively small but statistically significant. Additionally, the findings provide weak evidence for the emperor's own ideological position conditioning his endorsement effect. These results provide new insights into how supposedly non-political popular figures can influence the formation of political preferences. ${ }^{1}$
\end{abstract}

*Assistant Professor, Waseda Institute for Advanced Study, 1-21-1 Nishi Waseda, Shinjuku-ku, Tokyo, Japan (annaka@aoni.waseda.jp).

${ }^{\dagger}$ Assistant Professor, Political Science and International Relations Department, Kabanbay Batyr Str. 53, Nur-Sultan, Kazakhstan (gento.kato@nu.edu.kz).

1. Susumu Annaka and Gento Kato contributed equally to this work. This work was supported by JSPS KAKENHI, Grant Number 18J10578 and 19J14502. The pre-analysis plan for the analysis is registered at OSF https://osf.io/pkf7c (in Japanese). Additionally, the experimental design received approval from the Academic Research Ethical Review Committee at Waseda University (approval number: 2019-322). Also, authors would like to thank Munenori Kita and Ikuo Kume for their helpful comments. 
Present-day democracies often assign a strictly non-political role to certain powerful rulers such as monarchs. Such political systems are called constitutional monarchies; some typical examples of these include the United Kingdom, Sweden, and Japan. In constitutional monarchies, although monarchs "often have constitutional prerogatives that are similar to those of powerful presidents, such as the power of governmental dismissal, their constitutional status ensures that they are in no position to use these powers" (Schleiter and Morgan-Jones 2009, 499). Forbidden to use their political powers, monarchs in democracies are expected to play a symbolic role to unify their people.

While there has been much discussion on the legal definition of constitutional monarchs, the "real" connection between monarchs and politics has rarely been empirically studied. Thus, in this study, we examine whether the monarch of Japan, that is, the emperor, has any influence on the formation of ideological attitudes among Japanese voters. The emperor was once a powerful political and religious leader. However, at present, emperors in Japan are strictly forbidden to participate in any political activities due to the role they played during World War II. Nevertheless, the current emperor is respected by the majority of the Japanese public, from left to right ideologues. ${ }^{2}$ In addition, he has been expressing his opinions on important issues such as freedom of speech and peace and war, implying that he has the potential to influence public opinion.

To explore the political influence of the emperor, we design a survey experiment examining the regulation of public expression. Taking advantage of the dual nature of this ideological issue, we assess the effects of the emperor's endorsement on support for regulation under both a left-wing (i.e., the regulation of hate speech)and right-wing frame (i.e., the regulation of publicly funding anti-nationalistic exhibitions). We theorize that the emperor's endorsement of freedom of expression does reduce support for regulation, and this effect persists across different ideological frameworks. We compare the endorsement effect of

2. NHK (Nippon Hōsō Kyōkai; Japan Broadcasting Corporation) has beein conducting a Survey of Japanese Value Orientations since 1973 (Kono, Takahashi, and Hara 2010). In 2018, this survey reported that $77 \%$ of the Japanese public "respect" or have "favorable feelings" toward emperor Akihito (Aramaki, Murata, and Yoshizawa 2019). 
the emperor with that of a legal expert to evaluate their relative magnitudes. Additionally, we assess whether the ideological position of the emperor himself moderates his endorsement effect.

\section{The Endorsement Effect of a Symbolic Figure}

To our knowledge, there are virtually no studies on how a monarch's endorsement influences political attitudes. However, studies on the political influence of religious leaders and their messages are potentially relevant because the emperor was not only a ruler but also a religious figure in Japanese history. Here, religion plays a new political research agenda (GrzymalaBusse 2012). For example, McClendon and Riedl (2015) shows that self-affirming religious messages can encourage political participation.

In a similar vein, scholars have recently focused particularly on Pope Francis' messages. Similar to Japan's emperor, the Pope retains high popularity among the American and Euripean population, cross-cutting political ideologies. ${ }^{3}$ The Pope issued an encyclical in 2015 stating that people have a moral obligation to address climate change. ${ }^{4}$ Researchers have attempted to analyze the effects of this encyclical on the American public's perceptions of climate change using panel surveys (Li et al. 2016; Myers et al. 2017) and survey experiments (Schuldt et al. 2017; Buckley 2020).

All these studies find that exposure to the Pope's message has significant effects on attitudes toward climate change; however, the evidence regarding its connection with ideology is mixed. On one hand, Li et al. (2016) and Myers et al. (2017) found that exposure to the encyclical has a greater effect among liberals (i.e., Democrats) and those who have higher levels of prior concerns toward global warming. In contrast, Schuldt et al. (2017) and Buckley (2020) found that conservatives (i.e., Republicans) are more susceptible to agreeing with

3. As of 2020, $59 \%$ of American adults have been noted to have a "very" or "mostly" favorable view of Pope Francis. The rate plunged in 2018 when child abuse by a Catholic priest was uncovered. Until then, around $70 \%$ of the public held a favorable view since 2014 . Furthermore, over $70 \%$ of Catholics view the Pope favorably regardless of partisanship. (Nortey and Gecewocz 2020)

4. 'Laudato Si' ("Praise Be to You" ): On Care for Our Common Home on June 18, 2015. 
the Pope's message. In addition, the highly liberal nature of environmental issues prevents researchers from drawing simple and generalizable implications.

In the current study, we focus on the emperor's message on the regulation of public expression, and design a survey experiment. Two aspects are worth noting compared with research on the Pope in the United States. First, while the popularity of the emperor in Japan is comparable to that of the Pope in the United States, the emperor differs from the Pope or most other monarchs in that he is strictly not permitted to express political messages. Second, while concerns for environmental issues in the United States are considered strictly liberal, the regulation of freedom of expression in Japan can be framed as both left-wing (i.e., the regulation of hate speech) and right-wing (i.e., the regulation of publicly funding anti-nationalistic exhibitions). In the next section, we describe our experimental design, which takes advantage of this dual ideological nature.

\section{Experimental Design}

Our survey experiment was conducted between March 3rd and 9th, 2020 through an online survey platform Qualtrics. We recruited 1527 Japanese respondents (18 years or older) from the online cloud-sourcing platform Lancers. ${ }^{5}$ While a study shows that convenient samples from crowd-sourcing platforms generate similar experimental results as population-based samples (Mullinix et al. 2015), readers should avoid generalizing our findings for the larger population.

We designed the experiment using both across- and within-subject treatments. First, we asked respondents for their opinions on the regulation of public expression. We were interested in the interaction between opinion and ideology, but ideological predispositions cannot be assigned randomly. Instead, we described the issue in ways that left- and rightwing ideologues typically do. In this way, we could manipulate the "ideological framework"

5. Originally, we collected responses from 1939 respondents; however, due to a substantial overlap in samples between our pilot and main study, we ended up dropping 387 respondents. Additionally, 3 respondents exited the survey before the treatment assignment, and 22 respondents failed the satisficer screening question and were dropped from the analysis. 
of the issue and measure "ideological" opinions from both left- and right-wing perspectives.

This experiment had two ideological frameworks. For simplicity, we refer to the first as "hate speech" and the second as "biased history." These two framing conditions captured two ideologically contrasting ways in which the regulation of public expression is discussed in Japan today. First, around 2010, nativist protests against Zainichi Koreans (i.e., resident Koreans in Japan) had caught public attention. Such protests often used abusive and racist language. ${ }^{6}$ In 2016, the Japanese government enforced the Hate Speech Elimination Act, but active discussions regarding such regulations still continue today. For example, the city of Kawasaki enforced a municipal ordinance to criminalize violation of the hate-speech ban in 2020. Such criminal punishment rules were not included in the aforementioned national act (Kotani 2018). Given the nationalistic nature of hate speech, under this framework, regulation of public expression is often supported more among left-wingers than right-wingers.

Another major controversy on the regulation of public expression in Japan occurred in 2019. One of the exhibits at Aichi Triennale, a large-scale public-funded art exhibition held in Aichi, Japan, was suspended after complaints that the artworks were disgracing Japanese history. The targets include a sculpture of Korean comfort women ${ }^{7}$ and a short film with a scene of the emperor's photograph being burned. From the perspective of those who filed the complaints, these artworks are an expression of hatred against Japan and should not be displayed in public-funded art exhibitions. ${ }^{8}$ In contrast to hate speech, under this "biased history" frame, the regulation of public expression is often more supported among the rightwing than the left-wing. Therefore, the ideological tendencies of regulation supporters are expected to flip between hate speech and biased history frames.

In our questions, we randomly assign hate speech and biased history frames as follows:

6. One of the largest groups that organize such demonstrations is the Zaitokukai (Zainichi Tokken wo Yurusanai Shimin no Kai; this is a group of citizens who do not tolerate privileges for Zainichi Koreans) (Higashikawa 2017).

7. The issue of Korean comfort women during World War II has caused significant conflict between Japan and South Korea. The Japanese government claims that the issue has been officially resolved, but the Korean government disagrees.

8. For example, the Sankei Shimbun, a Japanese conservative newspaper, claimed on October 9, 2019, "exhibiting a film with a scene of the Showa emperor's portrait being burned is real hatred against Japan." 
In Japan, given the issue of [1: the increasing intensity of speeches/behaviors that ethnically/racially discriminate foreigners (hate speech) $\mid 2$ : artwork exhibitions that negatively portray Japanese culture/history at publicly-managed museums and events], there is a heated debate on the regulation expressions in public spaces. What is your opinion on the national/local government regulating expression in public spaces?

Respondents choose their answers from: "Should be regulated actively" (4); "Should be regulated if necessary" (3); "Hard to say if it should or should not be regulated" (2); "Should not be regulated if possible" (1); "Should not be regulated at all" (0); and "don't know" (dropped from analysis).

Immediately after their response to the first question, we confirm the answer provided by the respondent by repeating the question, but this time endorsing other views:

Regarding the issue of the national/local government regulating expression in public spaces, you answered "PREVIOUS ANSWER." There are various opinions on this matter, [A: among political/constitutional scholars, securing freedom of expression is thought to be fundamental to democracy and very important $\mid \mathrm{B} / \mathrm{C}$ : the current emperor emeritus, when serving as the emperor, stated that "securing freedom of expression is fundamental to democracy and very important" (on August 3, 1989) | C:, and also said that "our country gave great hardship to people in Korean Peninsula; in the past year, I expressed my deep grief on this matter" (on March 24, 1994)].9

After considering these [A: thoughts | B/C: words], what is your opinion on the national/local government regulating freedom of expression in public spaces?

9. There was a minor typo in the text for condition C (see Online Appendix). However, as no one reported this error in our pilot and main studies, we believe that it does not have a significant influence on our results. 
The second question offers the same set of answer options, but we randomly assign only one of the three endorsement conditions. All endorsements embrace freedom expression, and are intended to reduce the support for regulation of public expression. Furthermore, every endorsement is real and there is no deception. Condition A (expert endorsement) shows consensus among political and constitutional experts that freedom of expression is important for democracy. This condition is intended to capture the baseline endorsement of non-partisan expert figures (e.g., Johnston and Ballard 2016). Condition B (emperor endorsement) shows the emperor stating that freedom expression is important for democracy. ${ }^{10}$ Condition $\mathrm{C}$ (liberal emperor endorsement) build on condition B, mentioning that the emperor empathized with the Korean people for their experience during World War II. Conservative ideologues in Japan have been denying and/or arguing against the war crime charges by Korea. Therefore, we expect the emperor expressing empathy toward Koreans will lead to a perception that the emperor himself is ideologically liberal rather than conservative.

Given the above design, we have the following hypotheses. First, we check the validity of the ideological framing treatment:

H1: Ideology and support for regulation of expression in public spaces relate contrastingly under the hate speech and biased history frames. Liberals have higher support under the hate speech frame, while conservatives have higher support under the biased history frame.

After confirming H1, we hypothesize the effect of the emperor's endorsement:

H2: The emperor's endorsement of freedom of expression reduces the support for regulation of expression in public spaces.

While not explicitly stated in $\mathrm{H} 2$, we are also interested in the magnitude of the endorsement effect. The emperor's endorsement may (1) have a weak influence since he is seen as a "non-

10. We use "emperor emeritus" instead of emperor, as the current emperor only recently ascended to the throne, in May 2019, and has not made any significant statements yet. Given that the emperor emeritus was reigning for 31 years from January 1989 to April 2019, we believe the former emperor had a comparable or even more significant influence than the current emperor, in March 2020. 
political" figure; (2) be moderated by ideology frames, wherein more conservative ideologues are more susceptible or resistant to cues; and (3) have a strong influence since he is widely favored by the public. We explore the implications through the relative magnitude of the endorsement effect among political/constitutional experts and emperor under each ideology frame.

Finally, we also have an expectation from the emperor's personal ideological positions. The emperor is often seen as a generic symbolic figure, and not much attention has been paid to his personal preferences. However, in the context of his political standpoint exerting political influence, we can expect that the emperor's endorsement is most effective when his ideology frame, support for freedom of expression, and personal ideological position are logically aligned with each other. Then,

H3A: Under the hate speech frame, the effect of the emperor's endorsement is weaker if the emperor additionally shows empathy toward Koreans.

We expect a weaker endorsement effect for the liberal emperor under the hate speech frame, because his implied ideological position conflicts with his "freedom of expression" statement under this frame. On the other hand, we expect that:

H3B: Under the biased history frame, the effect of the emperor's endorsement is stronger if the emperor additionally shows empathy toward Koreans.

If the regulation of public expression is framed under biased history, the liberal position of the emperor aligns with the statement on freedom of expression.

\section{Results}

First, to assess if ideology frames functions as expected (H1), we estimate the standard OLS linear regression model using responses to the first question as outcome variables. ${ }^{11}$

11. Robust standard errors are used to estimate uncertainty. Alternate model specifications with control variables and ordinal logit yield essentially the same result. See Online Appendix for more details. 

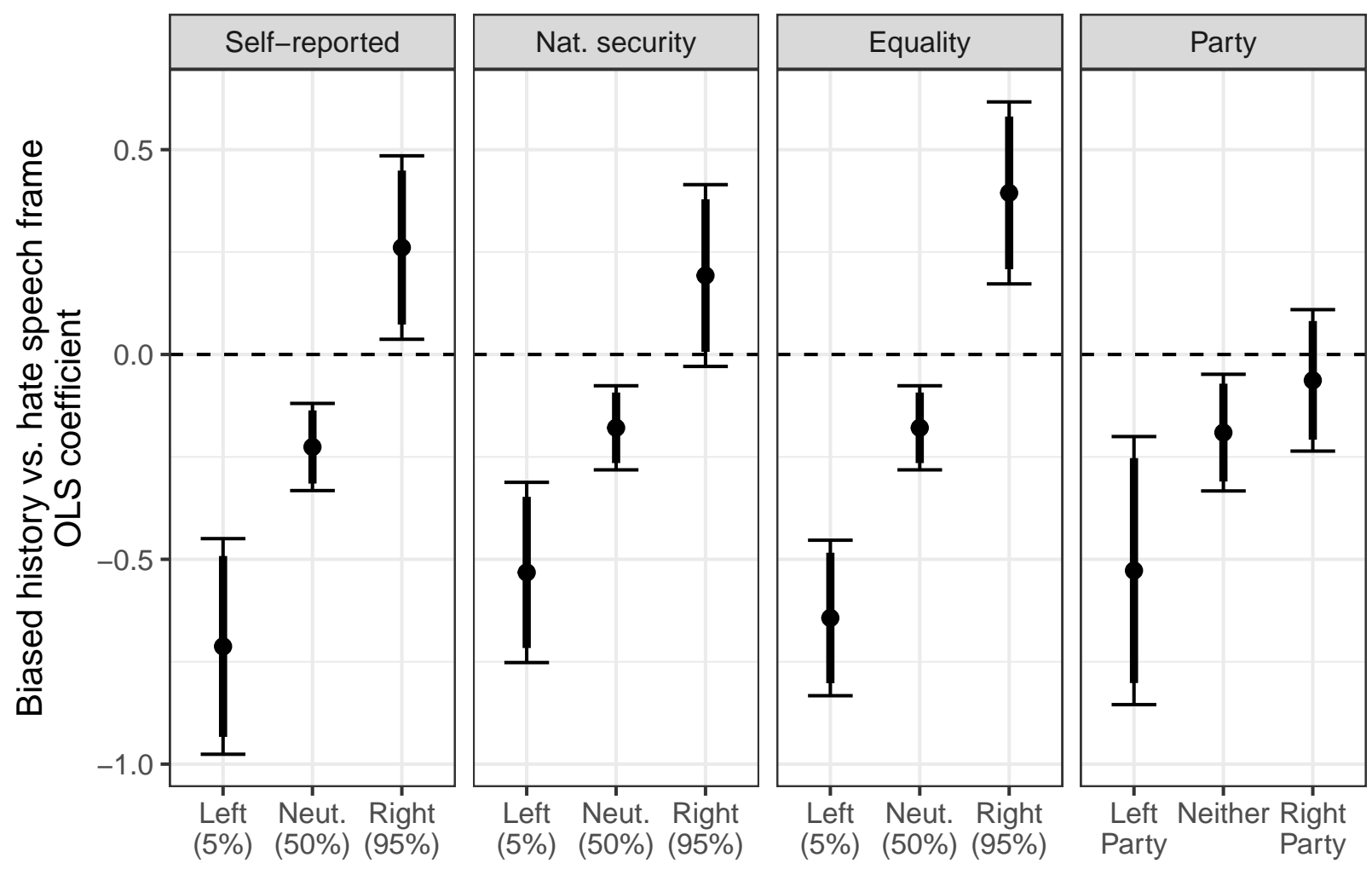

Ideological position

Figure 1: Ideology-moderated framing treatment effects (OLS, vertical lines represent confidence intervals; thin line $=95 \%$ and thick line $=90 \%)$

As independent variables, we enter the interaction of framing treatment (hate speech $=0$, biased history $=1$ ) and ideological predisposition. To check the robustness, models are estimated with four different ideology measures: self-reported 11-point ideology, scores from two-dimensional exploratory factor analysis of issue attitudes (first factor is interpreted as national security and second factor as equality), and party support. We scale all measures such that higher values represent a stronger right-wing ideology (See Online Appendix for detailed procedures).

Figure 1 shows the results for the ideology-moderated framing treatment effect. The figure shows the simulated conditional coefficient of the framing treatment variable for left-ideologues (5\%ile), the ideologically neutral (50\%ile, or median), and right-ideologues (95\%ile) for each type of ideology measure. The figure supports H1 across all ideology measures. For left-ideologues, the biased history frame decreases the support for regulation 

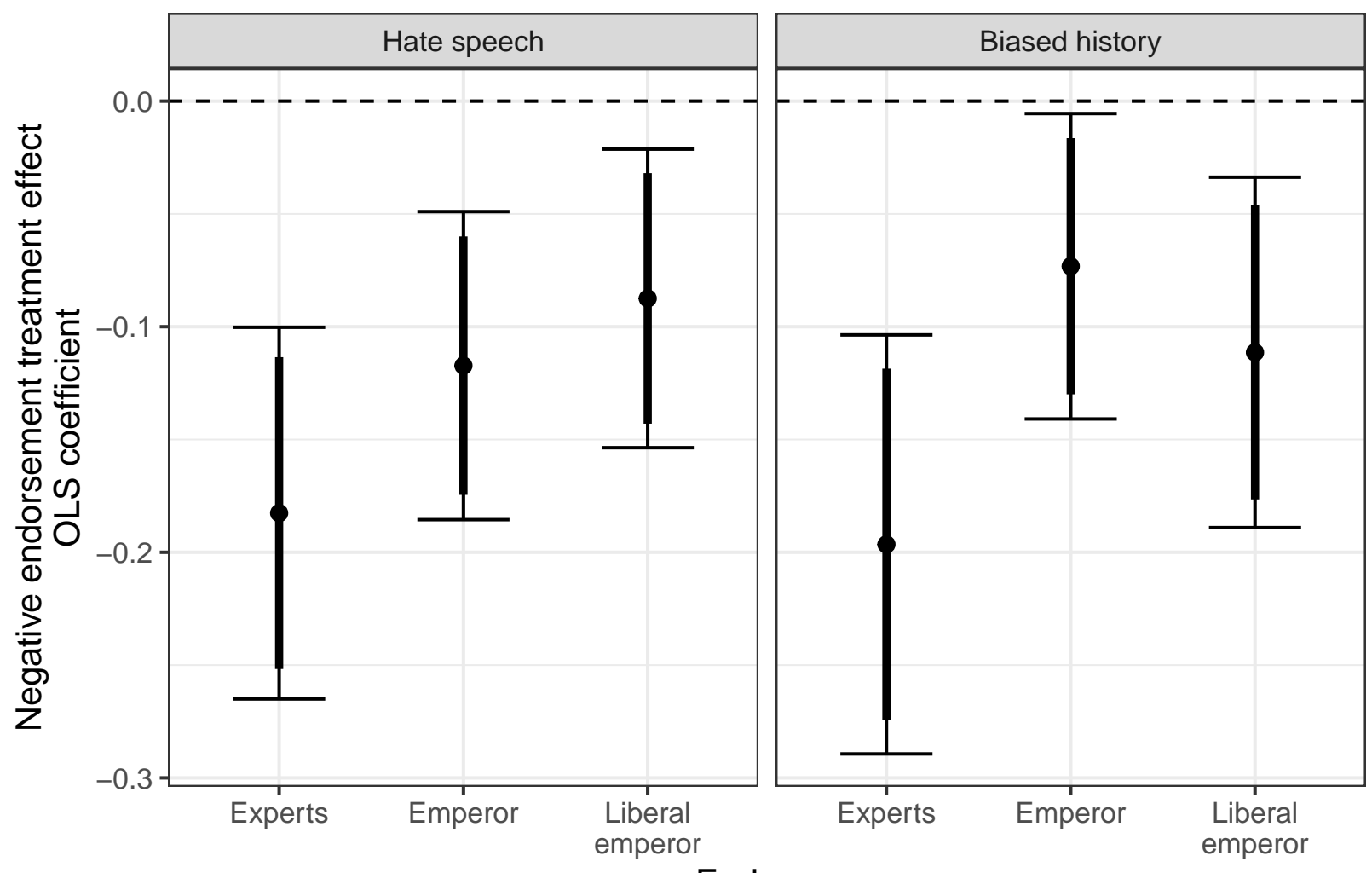

Endorser

Figure 2: Negative endorsement treatment effects (OLS, vertical lines represent confidence intervals; thin line $=95 \%$ and thick line $=90 \%$ )

compared to the hate speech frame. On the other hand, for right-ideologues, the relationship flips for three out of four measures (self-reported, national security, and equality), meaning that right-ideologues support regulation under the biased history frame than hate speech frame. For right-party supporters, the framing effect is not positive, and significantly weakened compared to left-party supporters. ${ }^{12}$

After confirming that each ideological frame successfully increases the support for regulation among corresponding ideologues, the next analysis incorporates the second question. In this analysis, we use a panel dataset pooling the answers for the first and second questions. Then, the linear OLS regression model is estimated using the interactions of endorsement treatments (before endorsement $=0$, after endorsement $=1$ ) and framing condition. Three

12. Note that the framing treatment effect is slightly negative for the ideologically neutral. This result implies that on average, subjects support regulations against hate-speech than against expressions disgracing Japanese history. 
endorsement treatment variables - expert, emperor, and liberal emperor - are considered to capture three different endorsers. ${ }^{13}$

Figure 2 shows the conditional coefficients of endorsement treatments by framing condition. First, all the coefficients are negative and statistically significant at the $95 \%$ level. This result supports H2: Negative endorsement by the emperor successfully decreases the support for regulation of public expression. Comparing endorsers, the emperor's endorsement effects are always smaller than those of political/constitutional experts. ${ }^{14}$ Within emperors, the liberal emperor's effect magnitude is slightly smaller than the emperor under the hate speech frame, but this pattern flips under the biased history frame. These patterns are consistent with $\mathrm{H} 3 \mathrm{~A}$ and $\mathrm{H} 3 \mathrm{~B}$, but the difference in magnitude is very small and statistically insignificant. Finally, comparing framing conditions, we do not find any significant differences in the magnitude of the emperor's endorsement effect, implying that the emperor's influence on regulation preferences cross-cuts ideologies.

\section{Discussion}

In this article, we design a survey experiment to assess the endorsement effects of the emperor, that is, the monarch of Japan, on public preferences toward the regulation of public expression. We use two unique ideology frames, hate speech and biased history, to explore if such an endorsement effect cross-cuts ideology. The result shows that emperor's endorsement does cross-cut ideology, although its effect is generally weaker than those of experts. Additionally, while the evidence is only suggestive, our result implies that the endorsement effect is potentially moderated by the personal ideological position of the emperor.

The current study is one of the first scientific attempts to assess the political influence of (supposedly) non-political symbolic figure, that is, constitutional monarchs, in democracies.

13. Robust standard errors clustered by subject ID are used to estimate uncertainty. Alternate model specifications with control variables and ordinal logit yield essentially the same result. See Online Appendix for more details.

14. The differences are statistically significant at the $90 \%$ level between experts and liberal emperor under hate the speech frame, at the $95 \%$ level between experts and emperor under the biased history frame. 
While this study focuses on the Japanese emperor, the conceptual significance of constitutional monarchs can be generalized beyond Japan (e.g., the Queen of England). Given our evidence that monarchs do have an influence on public opinion, there is significant potential for future studies to explore their roles in democracies. 


\section{References}

Aramaki, Hiroshi, Hiroko Murata, and Chiwako Yoshizawa. 2019. "How the Japanese Have Changed over 45 Years (Part II): From the 10th Survey on Japanese Value Orientations." The NHK Monthly Report on Broadcast Research 69 (6): 62-82.

Buckley, David T. 2020. "Religious Elite Cues, Internal Division, and the Impact of Pope Francis' Laudato Si'." Politics and Religion, 1-33. https://doi.org/10.1017/S17550483 $2000067 X$.

Grzymala-Busse, Anna. 2012. "Why Comparative Politics Should Take Religion (More) Seriously." Annual Review of Political Science 15 (1): 421-442. https://doi.org/10.1146/ annurev-polisci-033110-130442.

Higashikawa, Koji. 2017. “Japan's Hate Speech Laws: Translations of the Osaka City Ordinance and the National Act to Curb Hate Speech in Japan." Asian-Pacific Law \& Policy Journal 19 (1): 1-22.

Johnston, Christopher D., and Andrew O. Ballard. 2016. "Economists and Public Opinion: Expert Consensus and Economic Policy Judgments." The Journal of Politics 78 (2): 443-456. https://doi.org/10.1086/684629. eprint: https://doi.org/10.1086/684629.

Kono, Kei, Koichi Takahashi, and Miwako Hara. 2010. "The Survey of Japanese Value Orientations: Analysis of Trends over Thirty-Five Years." NHK broadcasting studies 8:162.

Kotani, Junko. 2018. "Proceed with Caution: Hate Speech Regulation in Japan." Hastings Constitutional Law Quarterly 45:603-622. 
Li, Nan, Joseph Hilgard, Dietram A. Scheufele, Kenneth M. Winneg, and Kathleen Hall Jamieson. 2016. "Cross-Pressuring Conservative Catholics? Effects of Pope Francis' Encyclical on the U.S. Public Opinion on Climate Change." Climatic Change 139, no. 3 (December 1, 2016): 367-380. https://doi.org/10.1007/s10584-016-1821-z.

McClendon, Gwyneth, and Rachel Beatty Riedl. 2015. "Religion as a Stimulant of Political Participation: Experimental Evidence from Nairobi, Kenya." The Journal of Politics 77 (4): 1045-1057. eprint: https://doi.org/10.1086/682717.

Mullinix, Kevin J., Thomas J. Leeper, James N. Druckman, and Jeremy Freese. 2015. "The Generalizability of Survey Experiments." Journal of Experimental Political Science, no. 2,109 .

Myers, Teresa A., Connie Roser-Renouf, Edward Maibach, and Anthony Leiserowitz. 2017. "Exposure to the Pope's Climate Change Message Activated Convinced Americans to Take Certain Activism Actions." Global Challenges 1 (4): 1600019. https://doi.org/10. 1002/gch2.201600019.

Nortey, Justine, and Claire Gecewocz. 2020. "Three-quarters of U.S. Catholics view Pope Francis favorably, though partisan differences persist." Pew Research Center.

Schleiter, Petra, and Edward Morgan-Jones. 2009. "Constitutional Power and Competing Risks: Monarchs, Presidents, Prime Ministers, and the Termination of East and West European Cabinets." The American Political Science Review 103 (3): 496-512.

Schuldt, Jonathon P., Adam R. Pearson, Rainer Romero-Canyas, and Dylan Larson-Konar. 2017. "Brief Exposure to Pope Francis Heightens Moral Beliefs about Climate Change." Climatic Change 141, no. 2 (March 1, 2017): 167-177. https://doi.org/10.1007/s10584016-1893-9. 